\title{
A Comparison Between Theoretical Prediction and Experimental Measurement of the Dynamic Behaviour of Spur Gears
}

Brian Rebbechi and B. David Forrester

Defence Science and Technology Organisation

Aeronautical Research Laboratory

Melbourne, Australia

and

Fred B. Oswald and Dennis P. Townsend

Lewis Research Center

Cleveland, Ohio

Prepared for the

Sixth International Power Transmission and Gear Conference sponsored by the American Society of Mechanical Engineers

Phoenix, Arizona, September 13-16, 1992 


\title{
A COMPARISON BETWEEN THEORETICAL PREDICTION AND EXPERIMENTAL
}

\section{MEASUREMENT OF THE DYNAMIC BEHAVIOUR OF SPUR GEARS}

\author{
Brian Rebbechi and B. David Forrester \\ Defence Science and Technology Organisation \\ Aeronautical Research Laboratory \\ Melbourne, Australia \\ and \\ Fred B. Oswald and Dennis P. Townsend \\ National Aeronautics and Space Administration \\ Lewis Research Center \\ Cleveland, Ohio 44135
}

\section{ABSTRACT}

A comparison was made between computer model predictions of gear dynamic behaviour and experimental results. The experimental data were derived from the NASA gear noise rig, which was used to record dynamic tooth loads and vibration. The experimental results were compared with predictions from the Australian Defence Science and Technology Organisation Aeronautical Research Laboratory's gear dynamics code, for a matrix of 28 load-speed points. At high torque the peak dynamic load predictions agree with experimental results with an average error of 5 percent in the speed range 800 to $6000 \mathrm{rpm}$. Tooth separation (or bounce), which was observed in the experimental data for light-torque, high-speed conditions, was simulated by the computer model. The model was also successful in simulating the degree of load sharing between gear teeth in the multiple-tooth-contact region.

\section{INTRODUCTION}

The dynamic behaviour of gears is important for a number of reasons - the dynamic load increment, the gear life, the gear noise, and the overall vibratory behaviour of the gear system. In aerospace applications, such as helicopter transmissions, all of these factors are relevant, and weight is also an important factor. A knowledge of dynamic load factors can assist in weight reduction.

The NASA gear noise rig was built to enable fundamental studies of gear dynamic behaviour to be carried out and to provide support to gear noise reduction programs. Oswald et al. (1991) compared dynamic load measurements from the NASA rig with predictions from the computer program DANST (Dynamic Analysis of Spur Gear Transmissions). This report continues that work, and compares the same experimental data with predictions from another model, developed at the Australian Defence Science and Technology Organisation (DSTO) Aeronautical Research Laboratory (ARL), designated ARL DYN.

The two models differ significantly. DANST (Lin et al. 1989, 1987) has four torsional degrees of freedom representing the motor, the gears, and the load. The shaft stiffness elements are represented by linear stiffnesses, and the tooth compliance by a variable stiff- ness. ARL_DYN (Rebbechi, 1991) models the gear in a way that allows the detailed contact conditions of each of the tooth pairs in contact to be separately represented. The model also includes shaft deflection. Although this has the disadvantage of increasing the complexity of the model, it has the advantage that the model parameters, such as the sliding friction coefficient, can be varied in a way that accords with the physical parameters.

The objectives of this work were (1) to evaluate predictions of dynamic load increment by using the ARL model and compare these with experimental results, and (2) to refine the model as necessary to match the predictions with the measured dynamic load curves.

\section{APPARATUS AND PROCEDURES}

The NASA Lewis gear noise rig (Fig. 1) was used for these tests. This rig features a single-mesh gearbox powered by a $150-\mathrm{kW}$ (200-hp) variable-speed electric motor. An eddy-current dynamometer loads the output shaft. The gearbox can be operated at speeds up to $6000 \mathrm{rpm}$. The rig was built to carry out fundamental studies of gear noise and the dynamic behaviour of gear systems. It was designed to allow testing of various configurations of gears, bearings, dampers, and supports. The gearbox is extensively instrumented for strain and vibration measurements.

A poly- $V$ belt drive was used as a speed increaser between the motor and the input shaft. A soft coupling was installed on the input shaft to reduce input torque fluctuations, which were caused by nonuniformity at the belt splice.

The test gears were identical spur gears (at 1:1 ratio) machined to American Gear Manufacturers Association (AGMA) class 13 accuracy. The gear profiles were modified with linear tip relief as shown in Fig. 2. Test gear parameters are shown in Table I.

Tooth root fillet strains were measured on the tensile and compressive sides of two successive teeth, at the $30^{\circ}$ tangency location (Cornell, 1980), Fig. 3. Dynamic strains were recorded for the four gages at a matrix of 28 load-speed test conditions: four speeds $(800,2000,4000$, and $6000 \mathrm{rpm})$ and seven torque levels $(16,31,47$, 
$63,79,94$, and 110 percent of the nominal torque of $71.8 \mathrm{~N}-\mathrm{m}$ (635 lb-in.)). The strain gage signals were transmitted through a slip-ring assembly to constant-current signal conditioners. The dynamic strain data were digitized by a digital data acquisition system, with sample rates of $50 \mathrm{kHz}$ per channel at the 2000-, 4000-, and 6000 -rpm speeds and $20 \mathrm{kHz}$ at the 800 -rpm speed. A once-perrevolution timing pulse provided an accurate angular position reference for digital resampling by linear interpolation. The resampled data were then synchronously averaged over several successive revolutions to reduce noise effects, such as the torque fluctuation from the drive belt.

The averaged strain data values were converted to normal tooth force (dynamic tooth load) by using calibration data measured under static conditions. The calibration apparatus and data reduction procedures are more fully described in Rebbechi et al. (1991) and Oswald et al. (1991).

\section{ANALYTICAL MODEL}

ARL DYN (Rebbechi, 1991), Fig. 4, considers both torsional and lateral displacements of the gears and can accommodate variable numbers of teeth in contact. The equations of motion were derived by considering dynamic equilibrium for moments and forces

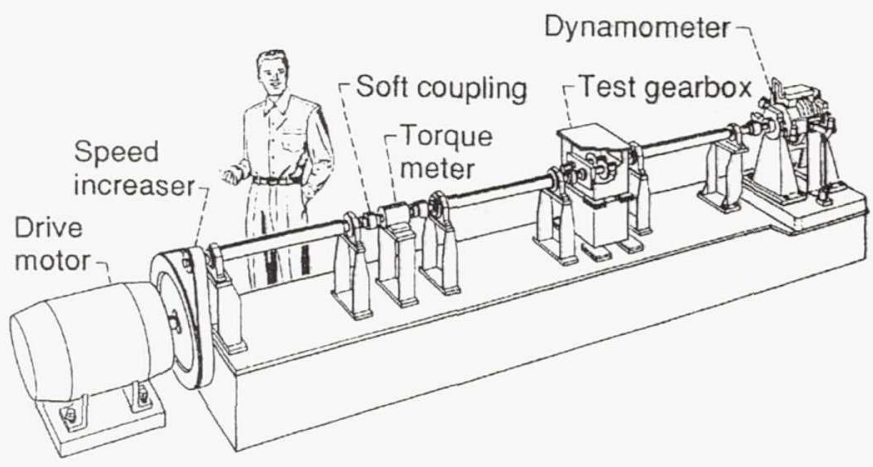

(a) Layout.

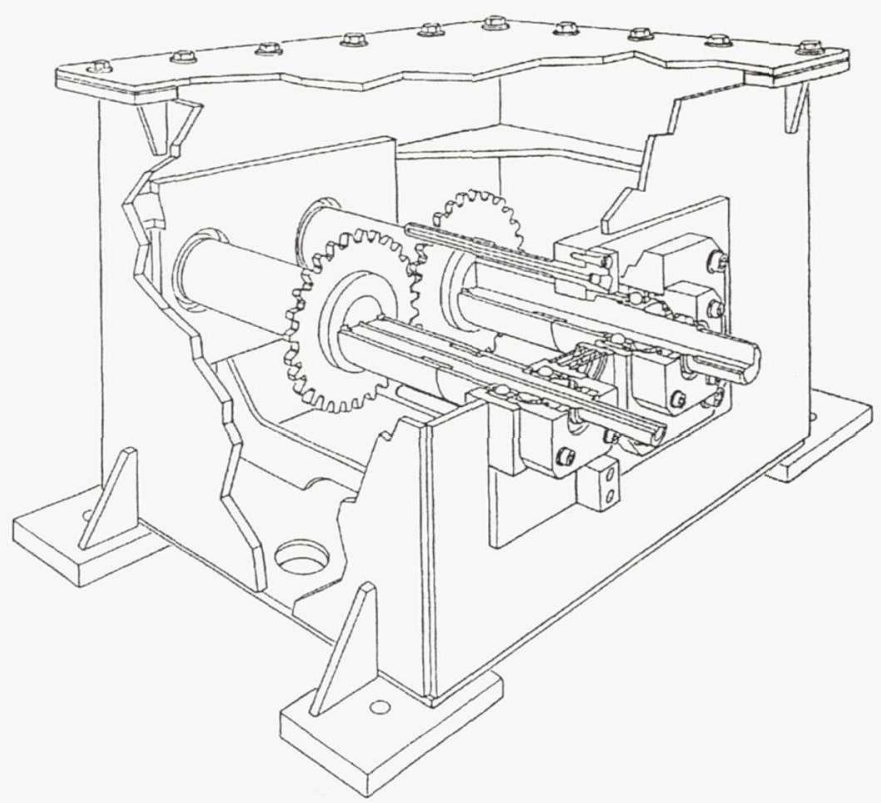

(b) Detail of gearbox.

Figure 1.-NASA gear noise rig. acting on the components of the system. Moments are taken about the axes of rotation. The mode of deflection of the gear teeth is taken as rotation about a point in the gear wheel at one tooth height below the base circle (see Rebbechi, 1983). The tooth stiffness, which varies with load position, is calculated according to a deflection equation in Merritt (1971). Forces acting through gear centers are resolved into coordinates $x_{1}, y_{1}, x_{2}, y_{2}$. This results in $[8+2(t-1)]$ equations of motion, where $t$ is the number of tooth pairs in contact. The set of equations can be reduced to $[7+(t-1)]$ equations by invoking the kinematic constraint equations for the gears in mesh.

To improve numerical accuracy, the equations involving gear body rotation $\theta_{1}, \theta_{2}$ were transformed to new coordinates $\Theta_{1}=\left(\theta_{1}\right.$ $\left.+n \theta_{2}\right) / 2$ (average rotation of gear pair) and $\Theta_{2}=\left(\theta_{1}-n \theta_{2}+c\right) / 2$ (relative rotation of gear pair), where $\theta_{1}$ and $\theta_{2}$ represent the rotation of the gear wheels, $n$ is the gear ratio, and $c$ is a constant used to make $\Theta_{2}=0$ if there are no errors. The new equations relate to (1) the absolute rotation, and (2) the relative rotation of the gear wheels. The gear dynamics code assembles the equations of motion in matrix form as shown in equation (1):

$$
[\mathbf{M}]\{\ddot{X}\}+[\mathbf{C}]\{\dot{X}\}+[\mathbf{K}]\{X\}=\{F\}
$$

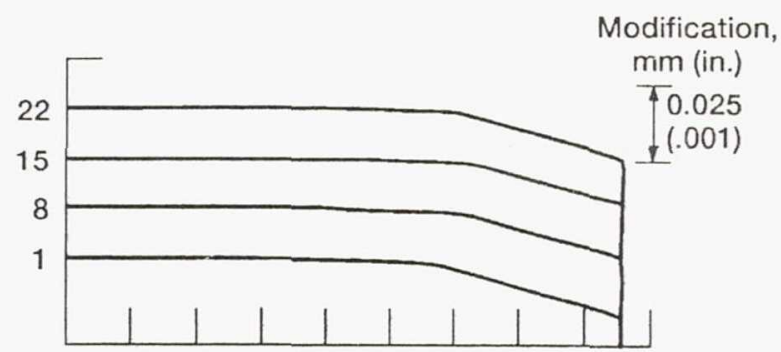

$\underset{\vdash}{\stackrel{5}{\circ}}$

(a) Driving gear.

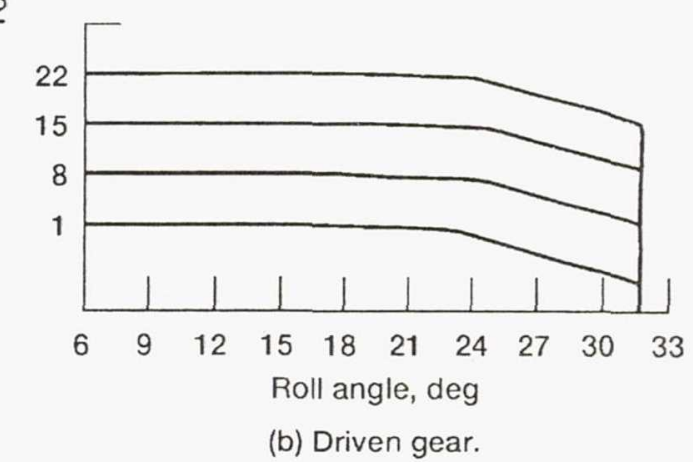

Figure 2.-Test gear profile traces.

TABLE I.-TEST GEAR PARAMETERS

Gear type . . . . . . . Standard involute; full-depth tooth

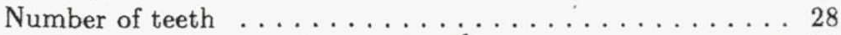
Module, mm (diametral pitch, in. ${ }^{-1}$ ) . . . . . $3.175(8)$ Face width, $\mathrm{mm}$ (in.) . . . . . . . . . . $6.35(0.25)$

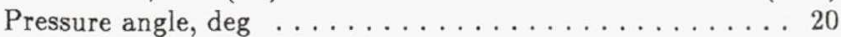

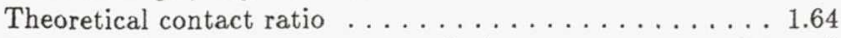
Driver modification amount, $\mathrm{mm}$ (in.) . . . . . . 0.023 (0.0009) Driven modification amount, $\mathrm{mm}$ (in.) . . . . . . $0.025(0.0010)$ Driver modification start, $\operatorname{deg} \ldots \ldots \ldots \ldots \ldots \ldots$ Driven modification start, deg $\ldots \ldots \ldots \ldots \ldots 24$ Tooth-root radius, $\mathrm{mm}$ (in.) . . . . . . . . 1.35 (0.053) Gear quality . . . . . . . . . . . . . AGMA class 13 Nominal (100 percent) torque, N-m (in.-lb) . . 71.77 (635.25) 


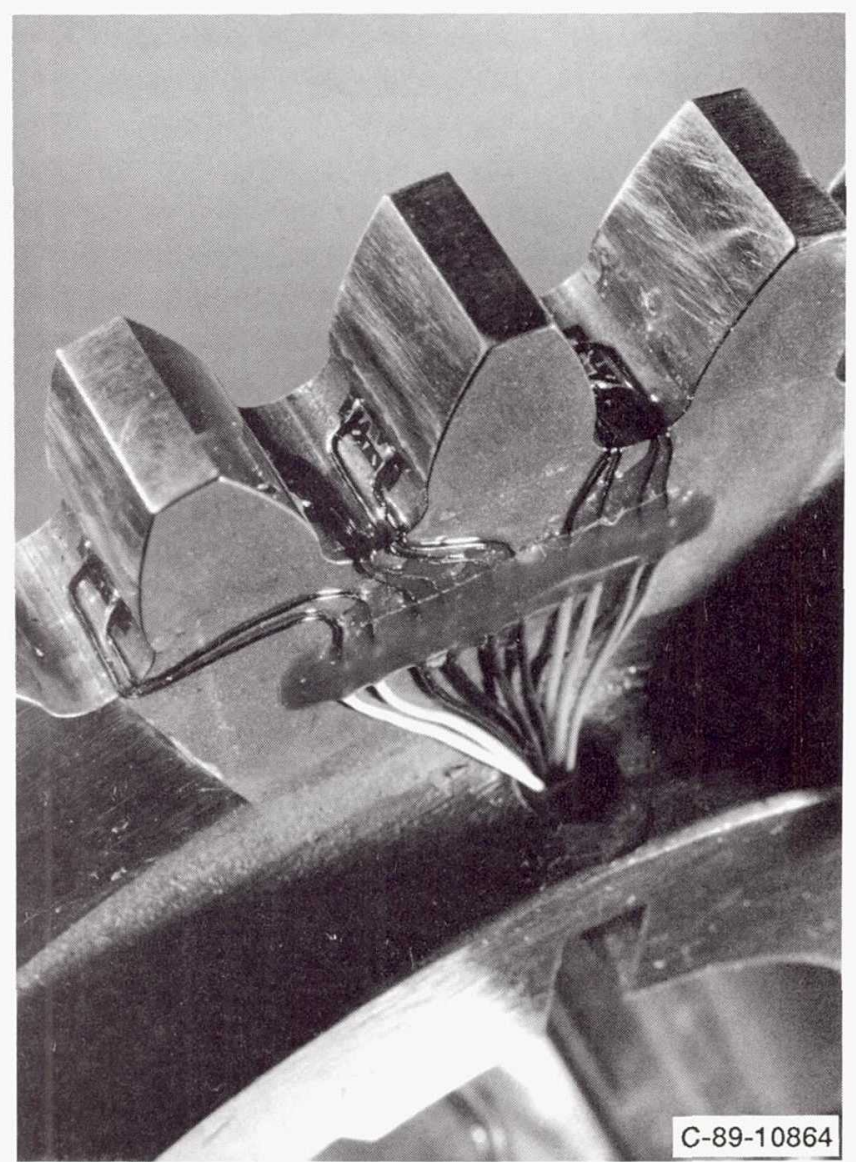

(a) Gage installation.

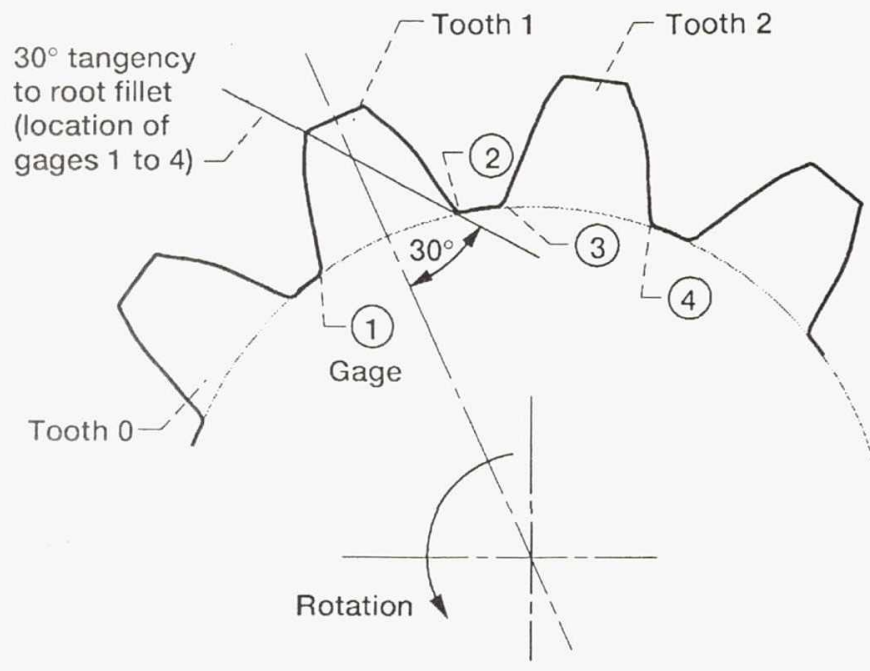

(b) Gage location.

Figure 3.-Strain gage installation and location on test gear.

where $\mathbf{M}, \mathbf{C}$, and $\mathbf{K}$ are square coefficient matrices representing the mass (inertia), damping, and stiffnesses, and $X$ and $F$ are vectors of displacements and forces (torques), respectively. The order (number of degrees of freedom) of equation (1) is $(6+t)$, where $t$ is the number of tooth pairs in contact. For low-contact-ratio gears, $t$ normally varies between 1 and 2 . If tooth separation (tooth bounce) occurs, $t$ may also be zero. Therefore, the degrees of freedom vary $\theta_{1}$ rotation of gear body 1

$\theta_{2}$ rotation of gear body 2

$\theta_{3-6}$ rotation of gear teeth

$x_{1}$ lateral displacement of gear wheel 1 , transverse direction

$y_{1} \quad$ lateral displacement of gear wheel 1, radial direction

$x_{2}$ lateral displacement of gear wheel 2, transverse direction

$y_{2}$ lateral displacement of gear wheel 2, radial direction

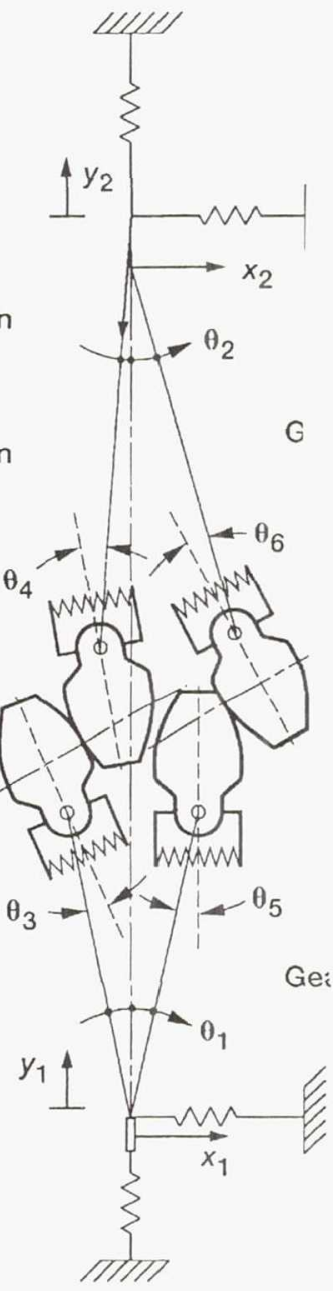

Figure 4.-Gear dynamics model.

between 6,7 , and 8 , depending on whether there are zero, one, or two pairs of teeth in contact. The $\mathbf{M}, \mathbf{C}$, and $\mathbf{K}$ matrices contain a number of nonlinear terms owing to the nonlinear kinematic constraints.

The dynamics code allows prescription of such features as profile errors and modification, shaft deflection (including interaction effects with conditions of tooth contact), tooth deflection (including resulting change of contact position and common normal direction), and tooth sliding friction. The friction coefficient for the gear mesh (the friction force divided by the normal force) was taken to be 0.06 . Values up to 0.10 were tried but made little difference in the results. Material damping in the gear tooth was modeled as viscous damping and expressed as the damping ratio (fraction of critical damping). Gear tooth material damping produces a significant effect. A damping ratio of 0.10 gave the best correlation with experimental data. The same damping ratio (0.10) was assumed for lateral bending of the shaft. The torsional shaft damping coefficient was $2.3 \times 10^{-5} \mathrm{~N}-\mathrm{m} /(\mathrm{rad} / \mathrm{sec})$. Changing the shaft damping values had little effect.

For input and output boundary conditions, steady external torques were assumed. The code solves the equations of motion with a Newmark-Beta numerical integration technique. The profile modification measured for the test gears (Fig. 2) was specified for the analysis. 


\section{RESULTS AND DISCUSSION}

Dynamic tooth loads computed from the strain gage readings were compared with the predictions of ARL DYN for dynamic tooth force. Initial runs of the computer model, although producing good results at high loads (with an average error in maximum tooth load of 5 percent), did not successfully characterise dynamic behaviour at light loads and high speeds. An example is shown in Fig. 5 , where at the roll angle of $21^{\circ}$, the predicted value is about 3.5 times the measured value.

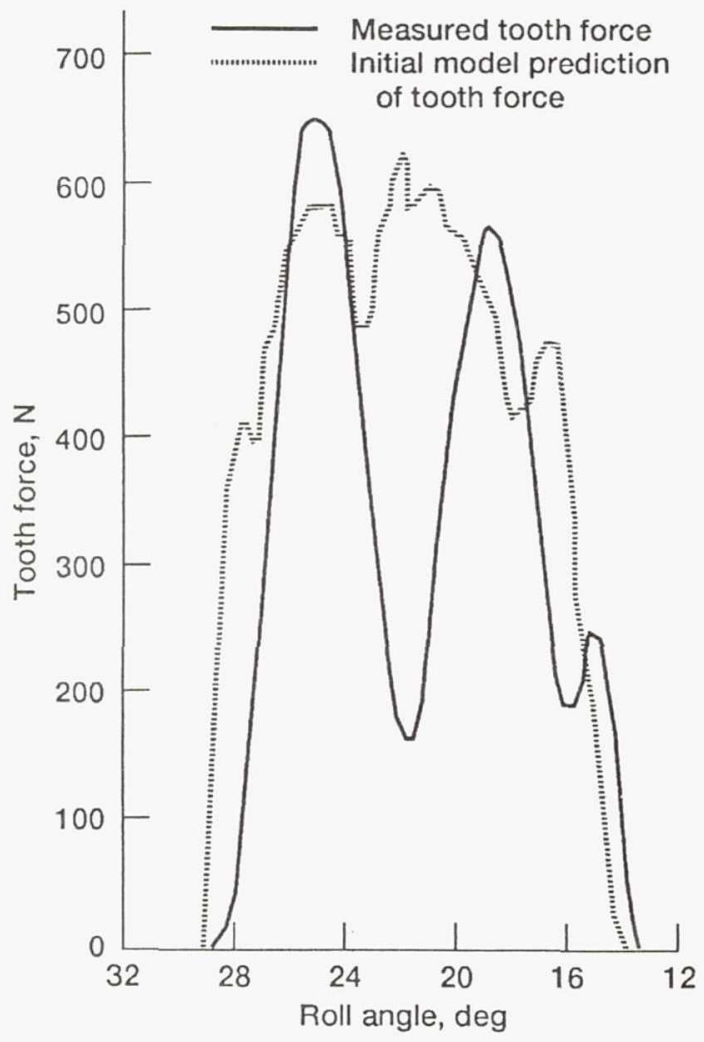

Figure 5.-Comparison between initial prediction of tooth force and measured result at $4000 \mathrm{rpm}$ and 31 -percent torque.

The experimental results were critically examined to evaluate reasons for the disagreement at light loads between analysis and experiment. A segment of these results is shown in Fig. 6. Here the dynamic tension strains at 31 -percent torque are plotted for four speeds in the range 800 to $6000 \mathrm{rpm}$. Each curve has three parts: (1) a region where the strain increases rapidly as the load is taken up by the tooth of interest; (2) a region of slowly declining static strain (with dynamic effect superimposed) where the entire load is carried by a single tooth pair; this region lies approximately between points A and B in Fig. 6; and (3) a region where the load is passed to the following tooth. It can be seen that the load-sharing regions ( 1 and 3 ), and thus the effective contact ratio, were virtually unaffected by speed. Speed had little effect on the dynamic load until point A in Fig. 6 was reached. The higher speeds show an "overshoot." As this overshoot changed only in magnitude as the speed increased, and did not change in angular position, it most likely resulted from a predominantly inertial effect, and not from a combined mass/stiffness (resonance) effect, where we would expect a phase shift.

The approximate displacement error for this gear tooth profile when lightly loaded is as described by Munro (1989) and is sketched in Fig. 7. Munro terms this type of profile correction as "long profile relief," where the relief extends from below the high point of single-tooth contact to the tooth tip. It appears that the overshoot in response evident in Fig. 6 arose from the inability of the gear pair to instantaneously adapt to the "separating mode" (where the driven gear leads the driving gear). As the gear speed increased, this effect became more marked. The dominant factors here are probably the gear wheel inertia, which relates to speed through the separating acceleration, and the external torque, which acts to reduce dynamic overshoot.

The effect of overshoot or tooth separation was reproduced in the computer model. Initially, the value used for gear wheel inertia did not include the inertias of the gear hub, shaft, spacers, or couplings. When these parts were accounted for, the inertia value increased by a factor of 4 . The tooth forces for the "light" and the "standard" (corrected) gears are compared in Fig. 8. The measured tooth force data are also shown for comparison. This result closely accords with and confirms the hypothesis of Munro (1989), who described the tendency of gears with long relief to separate at light loads.

The influence of shaft deflection was also considered. Owing to the construction of this test gearbox (Fig. 1), where the gears are centrally mounted on relatively long supporting shafts, it was at one stage thought that lateral deflection may be a cause of the tooth bounce observed when light loads are combined with high speeds. Dynamic tooth strains at $4000 \mathrm{rpm}$ are compared for seven torque levels in Fig. 9. The effect of tooth bounce can be seen in the curve for 16-percent torque. Here, the force vanishes around the pitch point, indicating that the teeth have lost contact. It is interesting to note that the tooth bounce shown here is not unique to the NASA gear noise rig but is also seen in the results of other researchers such as Tobe et al. (1977). Figure 10 compares the predicted dynamic tooth force for the normal gears with a case where the shaft stiffness is increased by a factor of 4 . There is little difference in the character of these curves.

The shaft deflection in the radial direction (along the line joining the gear centers) for both normal and stiff shafts is plotted in Fig. 11. As expected, the mean deflection was less when the stiffness was increased, but surprisingly the dynamic displacement increased. This increase in dynamic displacement for a stiffer shaft was apparently a resonance effect (note the phase shift of approximately $90^{\circ}$ between the curves). This indicates that shaft flexibility is not likely to be a contributing factor to the tooth bounce.

Dynamic load predictions for the model with the normal (heavier) gear wheels are compared with measured values in Fig. 12. Agreement is reasonable except in Fig. 12(c), at $6000 \mathrm{rpm}$ and 31-percent torque. The prediction shows tooth separation at this condition, but tooth separation was actually recorded at the lower speed of $4000 \mathrm{rpm}$ and the lighter torque of 16 percent (see Fig. 9). It is evident from these results that further refinement of the model is necessary to produce consistent results across the whole speed range. It is probable that the introduction of additional torsional degrees of freedom, representing the motor and the dynamometer, would aid in this regard, so that the dynamic load increments at different speeds could be magnified or reduced. The analysis was particularly successful in predicting the response in the load-sharing region (roll angle greater than $23^{\circ}$ or less than $19^{\circ}$ ).

The peak values of the dynamic load from both measured and predicted data are compared at four speeds $(800,2000,4000$, and $6000 \mathrm{rpm})$ for the highest torque level (110 percent) in Fig. 13. The predicted and measured data show the same trend (i.e., a minimum at about $4000 \mathrm{rpm}$ ), and the values agree within an average error of 5 percent. The static load line drawn in Fig. 13 is calculated from the external applied torque of 110 percent. The resulting force of $1894 \mathrm{~N}$ (426 lb) is computed from the torque divided by the base circle radius. 


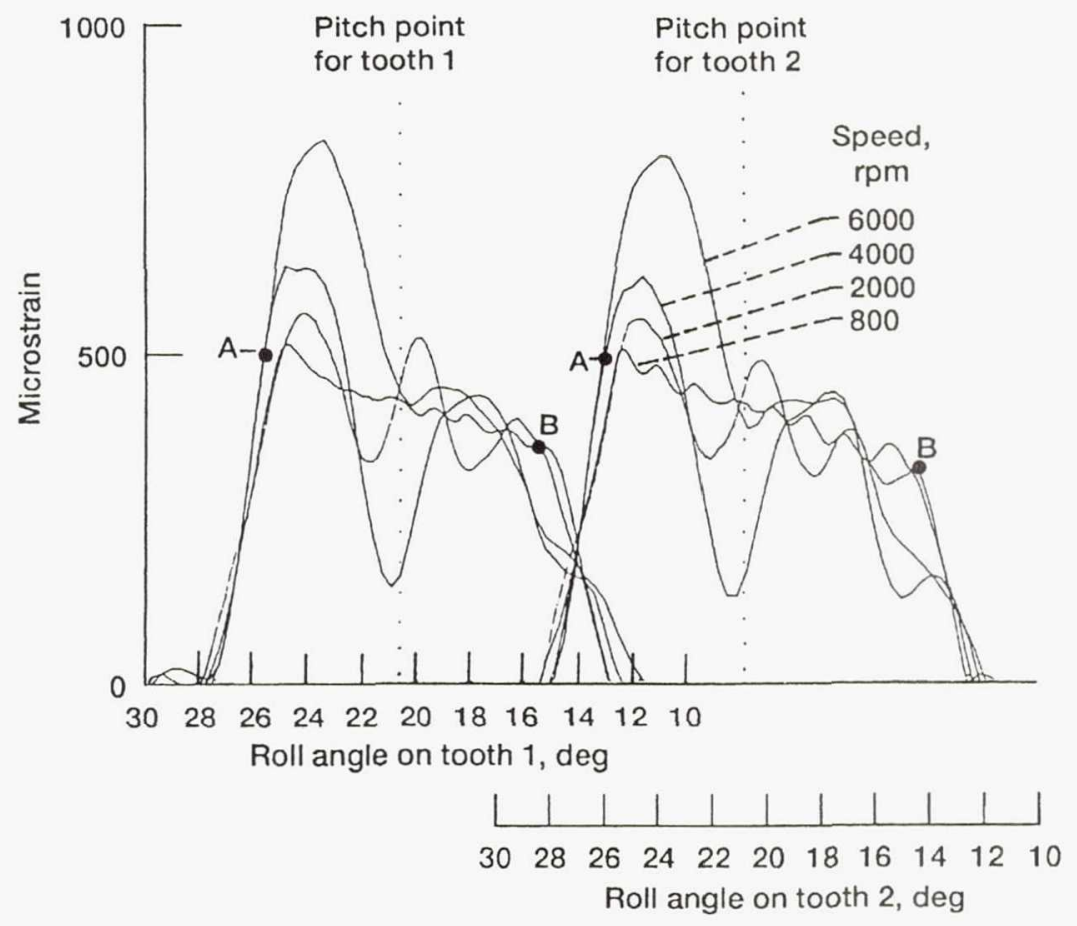

Figure 6.-Tension gage strain at 31 -percent torque and four speeds.

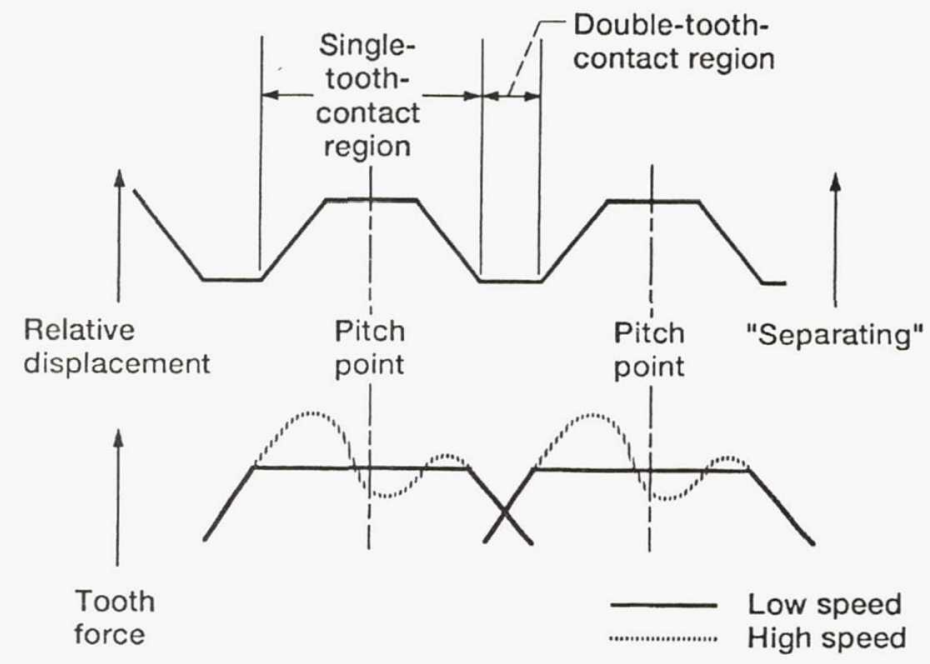

Figure 7.-Relative displacement in single- and double-toothcontact regions and effect of speed on dynamic load.

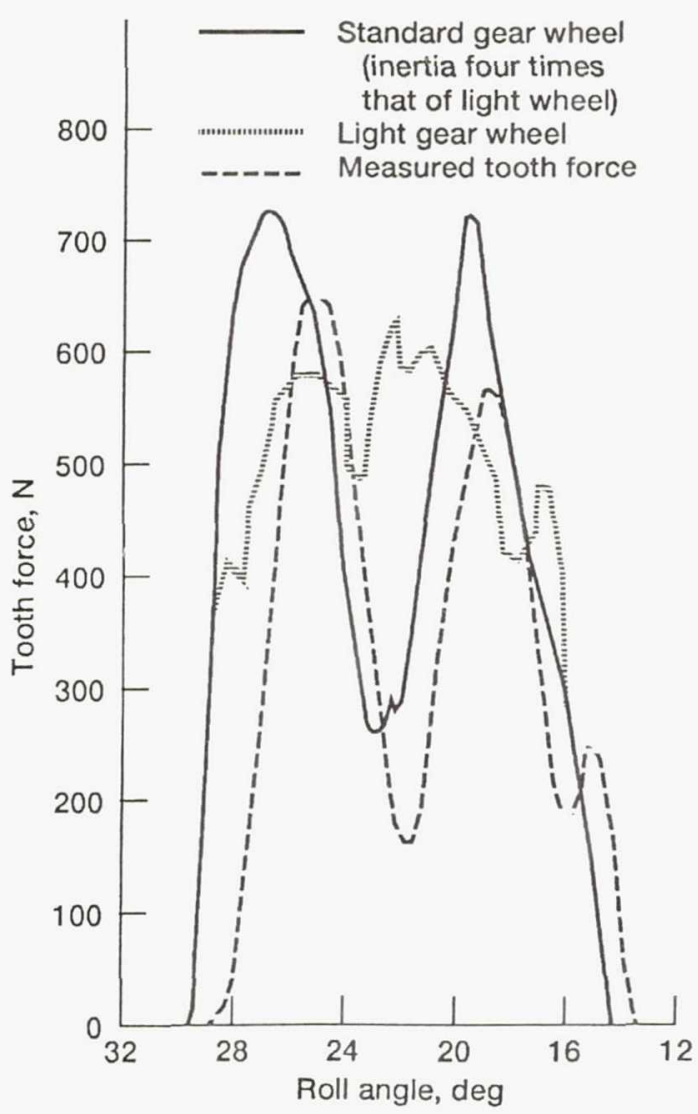

Figure 8.-Effect of gear wheel inertia on predicted dynamic tooth force at $4000 \mathrm{rpm}$ and 31 -percent torque. 


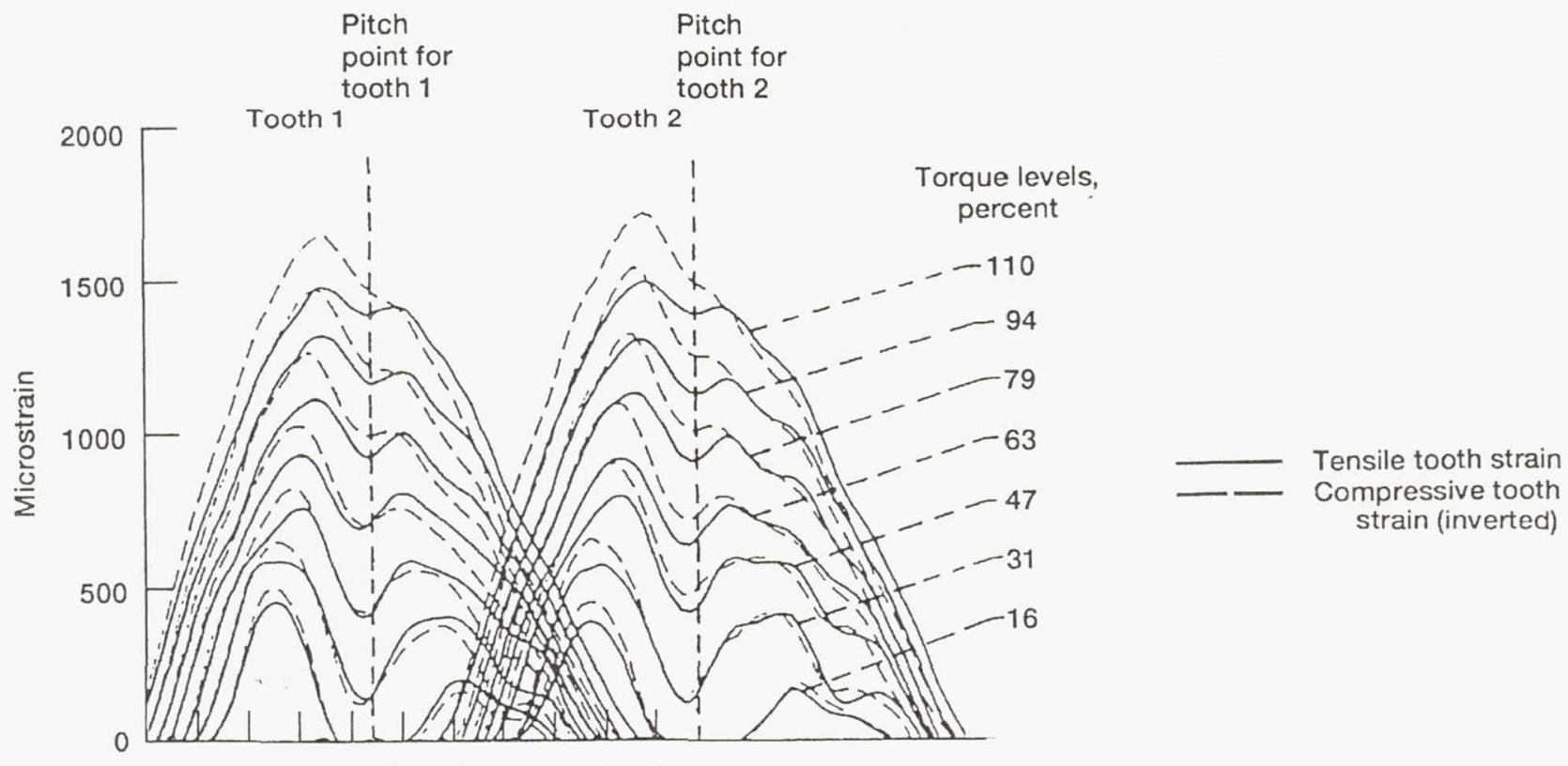

$\begin{array}{lllllllllll}30 & 28 & 26 & 24 & 22 & 20 & 18 & 16 & 14 & 12 & 10\end{array}$

Roll angle on tooth 1 , deg

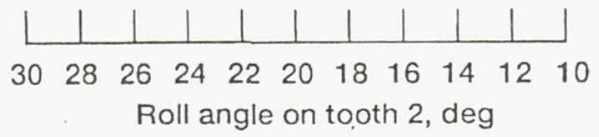

Figure 9.-Dynamic tooth strains at $4000 \mathrm{rpm}$ and seven torque levels.

Compressive strains are shown as positive for comparison with tensile data.
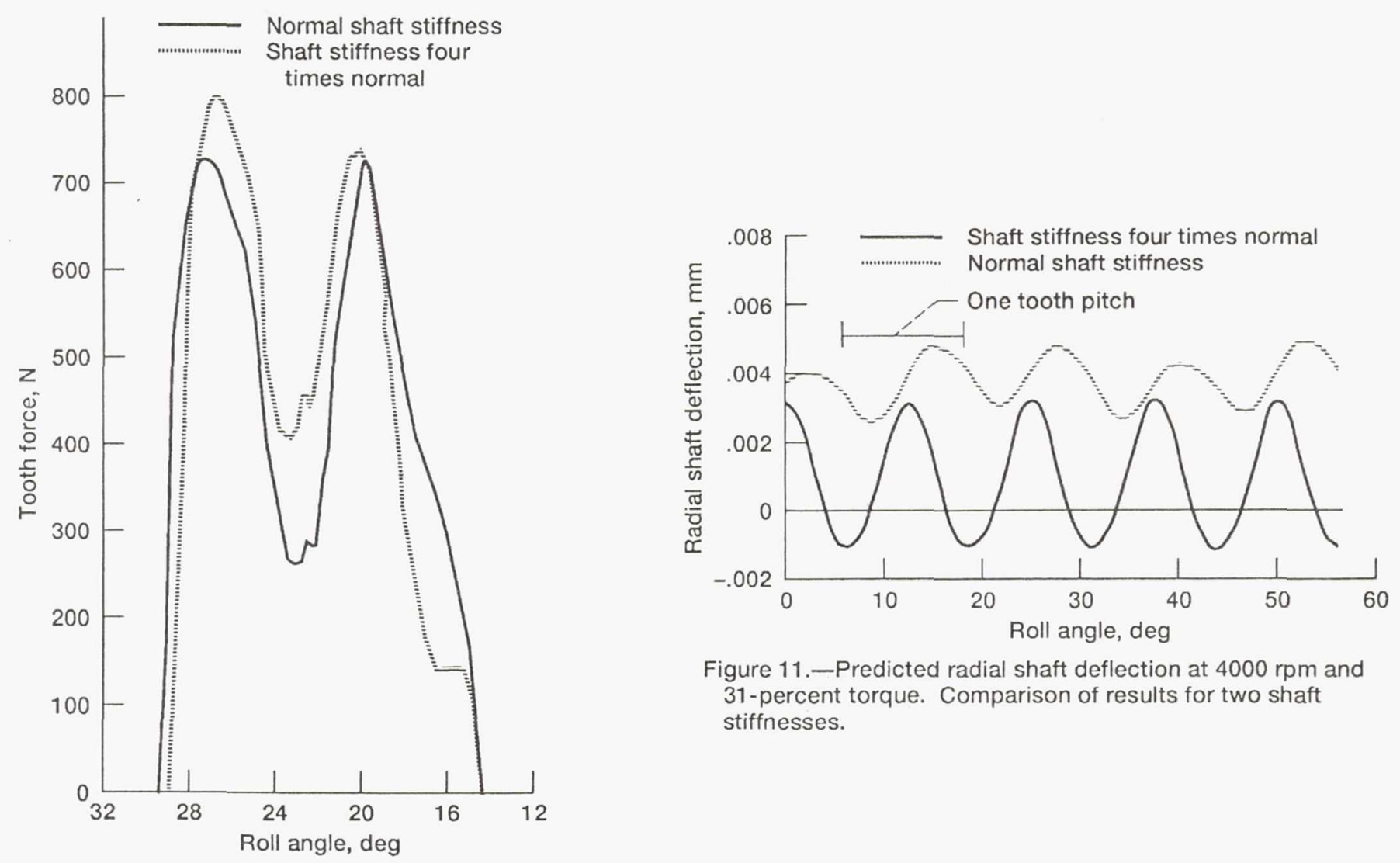

Figure 11.-Predicted radial shaft deflection at $4000 \mathrm{rpm}$ and 31-percent torque. Comparison of results for two shaft stiffnesses.

Figure 10.-Predicted dynamic tooth force at $4000 \mathrm{rpm}$ and 31 percent torque. Comparison of results for two shaft stiffnesses. 


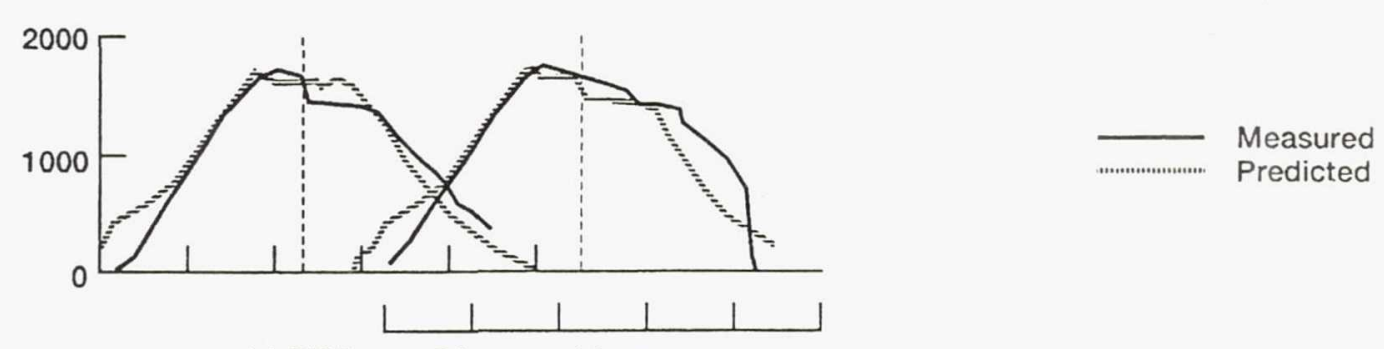

(a) $6000 \mathrm{rpm}$; 94-percent torque.

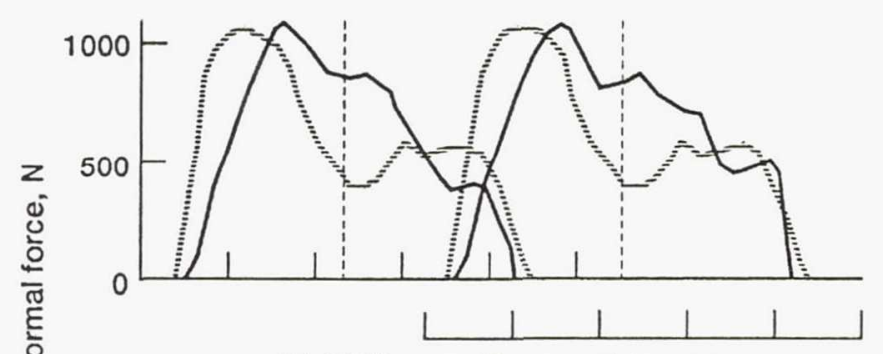

(b) $6000 \mathrm{rpm}$; 47-percent torque.

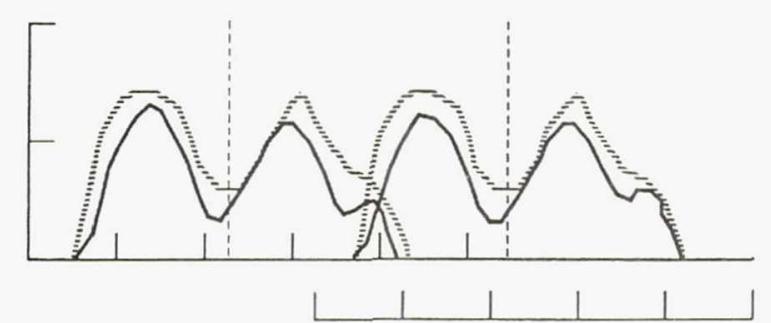

(d) 4000 rpm; 31 -percent torque.

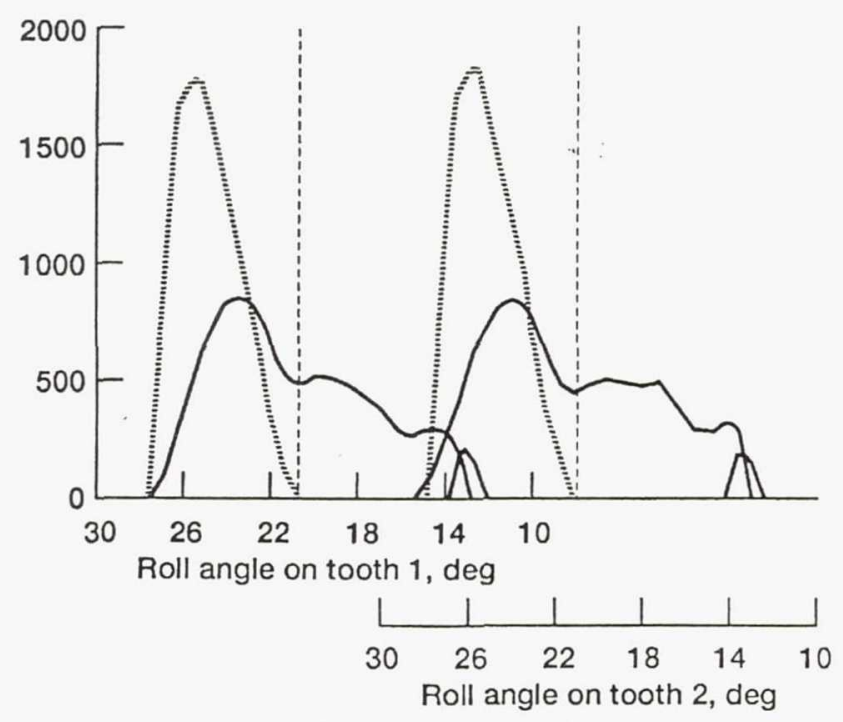

(c) $6000 \mathrm{rpm}$; 31-percent torque.
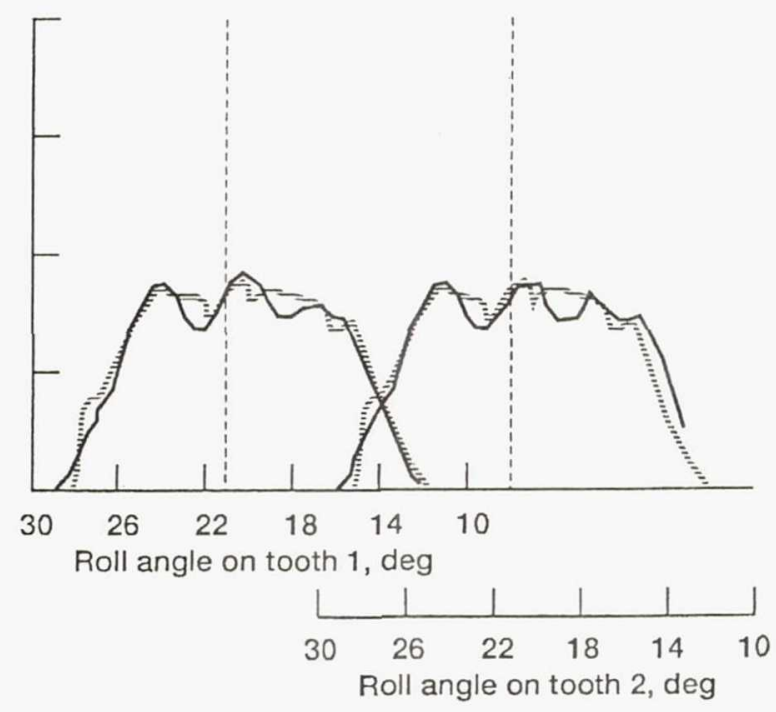

(e) $2000 \mathrm{rpm}$; 47 -percent torque.

Figure 12.-Comparison between predicted and measured dynamic tooth loads for normal gear wheels.

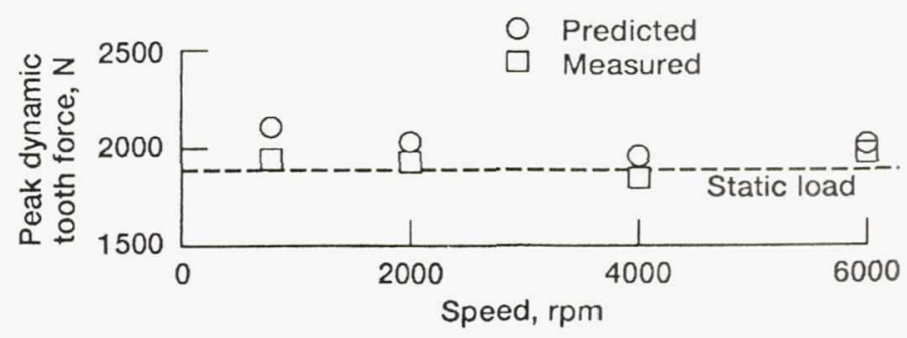

Figure 13.-Comparison between predicted and measured peak dynamic tooth load at 110-percent torque and four speeds. 


\section{CONCLUSIONS}

Experimental data for gear tooth dynamic load were compared with predictions from the Australian Defence Science and Technology Organisation Aeronautical Research Laboratory's gear dynamics code. The effects of lateral shaft stiffness and gear body inertia were examined by using the computer model to improve predictions of gear tooth bounce as observed at light loads and high speeds. The following results were obtained:

(1) Peak dynamic load predictions agreed with measured data within an average error of 5 percent for 110-percent torque and speeds ranging between 800 and $6000 \mathrm{rpm}$.

(2) Tooth separation (or bounce) was observed in the experimental data for light-load, high-speed operation. The computer model predicted tooth separation under slightly different conditions. The model shows that this phenomenon is primarily dependent on the operating conditions of speed and load and the physical parameters of tooth profile and gear body inertia. An increase in gear wheel inertia increases the likelihood of tooth separation.

(3) The analytical model was successful in simulating the degree of load sharing between gear teeth in the multiple-toothcontact region.

\section{REFERENCES}

Cornell, R.W., 1980, "Compliance and Stress Sensitivity of Spur Gear Teeth," ASME PAPER 80-C2/DET-24.

Lin, H.H., Townsend, D.P., and Oswald, F.B., 1989, "Profile Modification to Minimize Spur Gear Dynamic Loading," International Power Transmission and Gearing Conference, 5th: New Technologies for Power Transmissions for the 90's, ASME, New York, Vol. 1, pp. 455-465. (Also, NASA TM-89901, 1987.)
Lin, H.H., Huston, R.L., and Coy, J.J., 1987, "On Dynamic Loads in Parallel Shaft Transmissions, 1: Modelling and Analysis," NASA TM-100180.

Merritt, H.E., 1971, Gear Engineering, Pitman Publishing, London, pp. 221-222.

Munro, R.G., 1989, "The D.C. Component of Gear Transmission Error," International Power Transmission and Gearing Conference, 5th: New Technologies for Power Transmissions for the 90's, ASME, New York, Vol. 1, pp. 467-470.

Rebbechi, B., Oswald, F.B., and Townsend, D.P., 1991, "Dynamic Measurements of Gear Tooth Friction and Load," AGMA report 91-FTM-10. (Also NASA TM-103281.)

Rebbechi, B., 1991, "A Dynamic Model of Spur Gear Behaviour," ARL Report PROP-R-188, Aeronautical Research Laboratory, Melbourne, Australia.

Rebbechi, B., and Crisp, J.D.C, 1983, "Kinetics of the Contact Point and Oscillatory Mechanisms in Resilient Spur Gears," Proceedings of the Six World Congress on the Theory of Machines and Mechanisms, Halsted Press, New York, Vol. 1, pp. 802-808.

Oswald, F.B., Rebbechi, B., Zakrajsek, J.J., and Townsend, D.P., 1991, "Comparison of Analysis and Experiment for Dynamics of Low Contact Ratio Spur Gears," Proceedings of 13th Biennial Conference on Mechanical Vibration and Noise, ASME, 1991. (Also NASA TM-103232.)

Tobe, T., Sato, K., and Takatsu, N., 1977, "Statistical Analysis of Dynamic Loads on Spur Gear Teeth," JSME Bulletin, Vol. 20, No. 148 , pp. $1315-1320$. 
Public reporting burden for this collection of information is estimated to average 1 hour per response, including the time for reviewing instructions, searching existing data sources, gathering and maintaining the data needed, and completing and reviewing the collection of information. Send comments regarding this burden estimate or any other aspect of this collection of information, including suggestions for reducing this burden, to Washington Headquarters Services, Directorate for information Operations and Reports, 1215 Jefferson Davis Highway, Suite 1204. Arlington, VA 22202-4302, and to the Office of Management and Budget, Paperwork Reduction Project (0704-0188), Washington, DC 20503.

\begin{tabular}{|l|c|c|}
\hline 1. AGENCY USE ONLY (Leave blank) & $\begin{array}{c}\text { 2. REPORT DATE } \\
1992\end{array}$ & $\begin{array}{r}\text { 3. REPORT TYPE AND DATES COVERED } \\
\text { Technical Memorandum }\end{array}$ \\
\hline
\end{tabular}

\section{TITLE AND SUBTITLE}

A Comparison Between Theoretical Prediction and Experimental Measurement of the Dynamic Behaviour of Spur Gears

5. FUNDING NUMBERS

$$
\text { WU-505-63-36 }
$$

\section{AUTHOR(S)}

Brian Rebbechi, B. David Forrester, Fred B. Oswald, and Dennis P. Townsend

\section{PERFORMING ORGANIZATION NAME(S) AND ADDRESS(ES)}

NASA Lewis Research Center

Cleveland, Ohio 44135-3191

and

Propulsion Directorate

U.S. Army Aviation Systems Command

Cleveland, Ohio 44135-3191
9. SPONSORING/MONITORING AGENCY NAMES(S) AND ADDRESS(ES)

National Aeronautics and Space Administration

Washington, D.C. 20546-0001

and

U.S. Army Aviation Systems Command

St. Louis, Mo. 63120-1798
8. PERFORMING ORGANIZATION REPORT NUMBER

E-6953

\section{SUPPLEMENTARY NOTES}

Prepared for the Sixth International Power Transmission and Gear Conference sponsored by the American Society of Mechanical Enginecrs, Phocnix, Arizona, September 13-16, 1992. Brian Rebbechi and B. David Forrester, Defence Science and Technology Organisation, Aeronautical Rescarch Laboratory, Melbourne, Australia; Fred B. Oswald and Dennis P. Townsend, NASA Lewis Research Center. Responsible person, Fred B. Oswald, (216) 433-3957.

12a. DISTRIBUTION/AVAILABILITY STATEMENT $12 b$. DISTRIBUTION CODE

Unclassified - Unlimited

Subject Category 37

10. SPONSORING/MONITORING AGENCY REPORT NUMBER

NASA TM-105362

AVSCOM TR 91-C-009

\section{ABSTRACT (Maximum 200 words)}

A comparison was made between computer model predictions of gear dynamic behaviour and experimental results. The experimental data were derived from the NASA gear noise rig, which was used to record dynamic tooth loads and vibration. The experimental results were compared with predictions from the DSTO Aeronautical Research Laboratory's gear dynamics code for a matrix of 28 load-speed points. At high torque the peak dynamic load predictions agree with experimental results with an average error of 5 percent in the speed range 800 to $6000 \mathrm{rpm}$. Tooth separation (or bounce), which was observed in the experimental data for light-torque, high-speed conditions, was simulated by the computer model. The model was also successful in simulating the degree of load sharing between gear teeth in the multiple-tooth contact region.

\section{SUBJECT TERMS}

Spur gears; Gear dynamics; Gear load; Dynamic load; Strain gage testing; Dynamic analysis; Profile modifications

\begin{tabular}{l|c}
$\begin{array}{l}\text { 17. SECURITY CLASSIFICATION } \\
\text { OF REPORT } \\
\text { Unclassified }\end{array}$ & $\begin{array}{c}\text { 18. SECURITY CLASSIFICATION } \\
\text { OF THIS PAGE } \\
\text { Unclassified }\end{array}$ \\
\hline
\end{tabular}
19. SECURITY CLASSIFICATION OF ABSTRACT

Unclassified 
National Aeronautics and

Space Administration

Lewis Research Center

Cleveland, Ohio 44135

Ofticial Business

Penalty for Private Use $\$ 300$

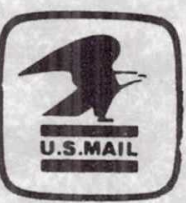

Postage and Fees Paid National Aeronautics and Space Administration NASA 451 